\title{
Growth of Staphylococcus aureus 2064 described by predictive microbiology: From primary to secondary models
}

\author{
Alžbeta Medved’ová, Adriana Havlíková, Lubomír Valík \\ Department of Nutrition and Food Quality Assessment, Faculty of Chemical and Food Technology, \\ Slovak University of Technology in Bratislava Radlinského 9, Bratislava 812 37, Slovakia \\ alzbeta.medvedova@stuba.sk
}

\begin{abstract}
The growth of Staphylococcus aureus 2064 isolate in model nutrient broth was studied as affected by temperature and water activity using principles and models of predictive microbiology. Specific rates resulting from growth curves fitted by the Baranyi model were modelled by the secondary Ratkowsky model for suboptimal temperature range (RTKsub) as well as the Ratkowsky extended model (RTKext) and cardinal model $(\mathrm{CM})$ in the whole temperature range. With the biological background of the RTKext model, cardinal values of temperature $T_{\min }=6.06{ }^{\circ} \mathrm{C}$ and $T_{\max }=47.9^{\circ} \mathrm{C}$ and water activity $a_{w \text { min }}=0.859$ were calculated and validated with cardinal values estimated by $\mathrm{CM}\left(T_{\min }=7.72^{\circ} \mathrm{C}, T_{\max }=46.73^{\circ} \mathrm{C}, a_{w \text { min }}=0.808\right)$. CM also provided other cardinal values, $T_{\text {opt }}=40.63^{\circ} \mathrm{C}, a_{w \text { opt }}=0.994$, as well as optimal specific growth rate of $1.97 \mathrm{~h}^{-1}\left(\right.$ at $T_{\text {opt }}$ and $\left.a_{w \text { opt }}\right)$. To evaluate the goodness of fit of all models, mathematical and graphical validation was performed and the statistical indices proved appropriateness of all the secondary models used.
\end{abstract}

Key words: food safety, prediction, Staphylococcus aureus, temperature, water activity

\section{Introduction}

Regardless the intensive effort in food hygiene, increase of knowledge and available resources, Staphylococcus aureus is still a challenge for food microbiologists and technologists, mainly in products with increased manual handling, which is documented by higher occurrence of $S$. aureus in food. For example in 2016, $17 \%$ of 962 milk samples tested in Italy and $21 \%$ of 940 food samples in Spain were positive for $S$. aureus. In 2017, the total of $655(3.6 \%)$ of the 18,361 food samples tested in the European Union were positive for this species. Moreover, one outbreak of staphylococcal intoxication occurred in the European Union in 2017 (EFSA Report 2017, 2018). In Slovakia, there were 174 cases of staphylococcal food-poisoning (SFP) outbreaks in 2016 and 14 cases in 2017. As the symptoms of SFP disappear quickly in healthy population, it is generally known that data underestimate the real situation in the food chain. In Slovakia occurrence of $S$. aureus was confirmed in $1.5 \%$ of 13,221 tested food samples in 2016 and in $2 \%$ of 12,291 tested samples in 2017 (Report on Zoonoses 2017, 2018).

The awareness of $S$. aureus in food and food environment results from its good growth in various food matrices, tolerance to low water activity and wide range of virulent factors, production of which is dependent on actual $S$. aureus growth ability. S. aureus is a versatile microorganism capable of quick adaptation to different environmental conditions (Mariutti et al., 2017) and persists even on plastic surfaces thanks to the interaction of teichoic acid, which is a part of Gram-positive bacteria cell membrane, with other surface polymers (Reffuveille et al., 2017). It is normally found on the skin of about 10-50\% asymptomatic humans (ECDC, 2017) and in animals. In the European Union, $56.4 \%$ of 225 animal samples tested in 2016 and $29.6 \%$ of 4,812 animal samples in 2017 were positive for $S$. aureus presence (EFSA Report 2017, 2018). In Slovakia, 17.8 \% positive samples of 1,949 tested animals in 2016 and $18.4 \%$ of 2,907 tested animal samples in 2017 were found positive (Report on Zoonoses 2017, 2018). Due to the production of a wide range of surface-associated factors, enzymes, toxins and superantigenic toxins, $S$. aureus is considered as a pathogen (Ote et al., 2011; Arbuthnott et al., 1990) but diseases caused by $S$. aureus do not necessarily originate only in direct tissue invasion (Mariutti et al., 2017). From the food point of view, the production of one or more of heatresistant staphylococcal enterotoxins (SEs) is the most crucial, because they are a causative agent of SFP outbreaks. The production of SEs is strongly dependent on environmental factors (Medvedová et al., 2017); thus the role of food microbiologists is to prevent $S$. aureus to grow and subsequently to produce SEs. In this context, predictive microbiology and its models represent a very useful tool.

As defined by Ross and McMeekin (1994), predictive microbiology is based on the premise that responses of microbial populations to environmental factors are reproducible, and that it is possible to predict microbial responses from past observations 
considering the environment in terms of identifiable dominating constraints. Based on cultivation experiments, the growth (or sometimes inactivation) of microorganisms is defined and subsequently described by primary models. These are defined by the change of microbial count as a function of time $(N=f(t))$ in constant conditions and their result is the definition of growth parameters (specific growth rate $\mu$, lag phase duration lag, etc.). In a next step/ advantage of predictive microbiology, the effects of changing environmental conditions (temperature, water activity, $\mathrm{pH}$, etc.) on microbial growth parameters can be described by the use of secondary models (Valík et al., 2019; Dubois-Brissonnet et al., 2015). Applying appropriate secondary models, cardinal values of environmental factors enabling growth of selected microorganisms can be defined. Finally, tertiary models are available in predictive microbiology. They include databases, fitting utilities, growth/no growth predictions, probability models and risk assessment modules enabling a wide range of applications such as HACCP system support, product and process design, shelf life assessment, sampling plans and experimental design and education (Valík et al., 2019).

However, to reliably and precisely predict microbial response to changing environmental factors, the adequate model has to be used. As stated by McMeekin et al. (2008), the process of model building in not simply a matter of finding an equation describing a single or some data sets. The equation should be based on biological observations; it should provide useful information about the relation between the microorganism and its environment. Moreover, the confidence in predictions significantly increases when different models or models from different sources provide comparable estimates of environmental influence on the microbial population behavior (Wood, 2016; McMeekin et al., 2008). Therefore, application of different secondary models (Ratkowsky model RTKsub, Ratkowsky extended model RTKext and cardinal model CM) describing the simultaneous effect of temperature and water activity on the growth of isolate S. aureus 2064 in model nutrient broth has been studied. Furthermore, the cardinal values of temperature and water activity of the isolate were defined and verified.

\section{Materials and methods}

\section{Microorganism}

The effect of simultaneous effect of temperature $(8,10,12,15,18,21,25,30,35,37,39,43,46$ and $50{ }^{\circ} \mathrm{C} \pm 0.5{ }^{\circ} \mathrm{C}$ ) and water activity $\left(a_{w}\right.$ ranging from 1.0 to 0.84 ) on growth of S. aureus 2064 was studied.
The identity of this isolate was earlier confirmed by Medved’ová et al. (2011).

\section{Media}

The isolate was maintained on slopes of Plate Count Agar (PGA; Difco, Le Pont de Claix, France) at $6 \pm 1{ }^{\circ} \mathrm{C}$. Its standard inoculum $\left(0.3 \mathrm{~mL}\right.$ from $10^{3} \mathrm{di}-$ lution of an $18 \mathrm{~h}$ isolate culture grown on PCA agar at $37^{\circ} \mathrm{C}$ ) was inoculated aseptically into $300 \mathrm{~mL}$ of pre-tempered glucose-tryptone yeast extract broth (GTYE; Difco, Le Pont de Claix, France) to reach

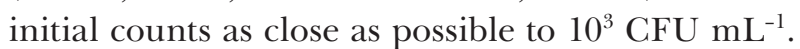
The samples were incubated in three parallels under static aerobic conditions at selected temperatures and $a_{w}$ values. The $a_{w}$ values of GTYE broth were set by an addition of NaCl (Sigma-Aldrich, Buchs, Switzerland) according to Rödel et al. (1979) and controlled by an $\mathrm{a}_{\mathrm{w}}$-meter (Aw-Sprint TH500, Novasina, Lachen, Switzerland).

\section{Counts of S. aureus 2064 in growth media}

At chosen time intervals, depending on actual temperature and $a_{w}$, cell numbers of $S$. aureus 2064 were determined according to ISO 4833-1:2013 on PCA agar (Sigma-Aldrich, St. Louis, USA).

\section{Fitting the growth curves and primary modelling}

S. aureus 2064 growth parameters were analysed, fitted and calculated using the DMFit Excel Add-in package version 3.5 (ComBase managed by the United States Department of Agriculture-Agricultural Research Service, Washington, DC, USA and the University of Tasmania Food Safety Centre Hobart, Australia) that incorporates the mechanistic model of Baranyi and Roberts (1994). Actual counts were plotted against time and fitted by a model for the estimation of $\mu$ and further analysed by secondary models using the Microsoft Office version 2013 (Microsoft, Redmond, Washington, USA) and the Statistica data analysis software system, version 10.0 (Tibco Software, Inc., Palo Alto, USA).

\section{Secondary modelling}

Growth parameters from each individual growth curve were analysed by secondary models. Specific growth rate $(\mu)$ was modelled as a function of the incubation temperature $(T)$ in the suboptimal temperature range at all studied $a_{w}$ values according to the Ratkowsky model (RTKsub):

$$
\sqrt{\mu}=b\left(T-T_{\min }\right) \times \sqrt{\left(a_{w}-a_{w \min }\right)}
$$

where $T_{\min }$ and $a_{w \min }$ are the temperature or $a_{w}$, respectively, below which no growth is observed. Growth parameters estimated at $43{ }^{\circ} \mathrm{C}$ and $46{ }^{\circ} \mathrm{C}$ $(n=38)$ were excluded from the suboptimal tem- 
perature data set. All model parameters $\left(T_{\min }, a_{w \text { min }}\right.$ and $b$ ) were calculated by non-linear regression analysis (Microsoft Excel and Statistica v. 10.0). To describe the simultaneous effect of $a_{w}$ and temperature in the whole range of these environmental factors, the extended model of Ratkowsky (RTKext) was used (Ratkowsky et al., 1983):

$$
\begin{gathered}
\mu_{\max }=b\left[\left(T-T_{\min }\right) \times\left\{1-\exp \left[c-\left(T-T_{\max }\right)\right]\right\}\right]^{2} \times \\
\times\left(a_{w}-a_{w \min }\right) \times\left\{1-\exp \left[d\left(a_{w}-a_{w \max }\right)\right]\right\}
\end{gathered}
$$

where, $T_{\min }$ and $a_{w \min }$ have the same meaning as previously, $T_{\max }$ and $a_{w \max }$ are the temperature or $a_{w}$, respectively, above which no growth occurs.

Cardinal model (CM) was used to describe the cumulative influence of temperature and $a_{w}$ on the microbial growth rate. Maximum specific growth rate was subjected to secondary modelling in relation to the incubation temperature (Rosso et al. 1993). The combined effect of temperature and $a_{w}$ was determined according to the gamma concept (Zwietering et al., 1991) based on individual cardinal models (Rosso et al., 1993):

$$
\mu_{\max }\left(T, a_{w}\right)=C M\left(T, a_{w}\right)=\mu_{\mathrm{opt}} \times \tau(T) \times \gamma\left(a_{w}\right)
$$

where $\tau(T)$ and $\gamma\left(a_{w}\right)$ are in Eqs. 4 and 5, where $T_{\text {opt }}$ is the temperature at which the maximum specific growth rate equals its optimal value, $\mu_{\mathrm{opt}}$.

\section{Goodness of fit}

To evaluate the goodness of fit of mathematical models, several mathematical and statistical indices were used. The ordinary least-squares criterion and regression coefficient $\left(R^{2}\right)$ were used to fit the models to the data. The goodness of fit of the modelling approach was assessed by the root mean square error (RMSE), which measures the average deviation between the observed and predicted values (Garcia et al., 2011). Also standard error of prediction (\%SEP) as reported Zurera-Cosano et al. (2006) and the per cent of variance $(\% V)$ as reported Daughtry et al. (1997) were used.

\section{Results and discussion}

A typical representation of an increase of bacterial culture with time is a sigmoid curve, as it is also depicted in Fig. 1. In a given environment allowing growth of bacterial population, typical phases of the growth curve are visible. First is the lag phase characterized as an adjustment period of the cells to the new environment; the growth phase is characterized by exponential increase of cells defined by specific growth rate $(\mu)$ and finally, the stationary phase during which the increment of cells is equal to their inactivation rate. The most worldwide used primary model describing the dynamics of bacterial cultures growth is the model introduced by Baranyi and Roberts (1994). Its main advantage is that the definition of the lag phase is independent of the growth curve shape and the effect of previous environment is separated from that of the present environment (Baranyi et al., 1993).

This model was also successfully applied ( $R^{2}$ ranging from 0.973 to 0.998 ) to describe the growth dynamics of isolate $S$. aureus 2064 at $39^{\circ} \mathrm{C}$ affected by changing $a_{w}$ values. The temperature of $39{ }^{\circ} \mathrm{C}$ was chosen from the temperature rage since almost optimal growth of the 2064 isolate was observed, as it will be discussed further. At almost all studied $a_{w}$ values; the growth curves of the isolate had a typical sigmoid shape. The only exception was the experiment at $a_{w}=0.842$, when only the growth inhibition of the isolate was noticed without any previous adaptation phase to such inhospitable conditions.

In the secondary phase of predictive modelling, the effect of environmental factors, e.g. $a_{w}$ and/or temperature on the growth parameters is described (Valík et al., 2019; Dubois-Brissonnet et al., 2015). Experimental data (points in Figures 1-3) are compared to the microorganisms behaviour (graticule in Figures 1-3) predicted by the selected model. Reliability and accuracy of the model are subsequently evaluated within the validation process.

To simply and quickly describe the effect of temperature and $a_{w}$, the Ratkowsky model (RTKsub; Eq. 1; Ratkowsky et al., 1983) was used for the data set of 209 growth parameters. The disadvantage of RTKsub model is that it is applicable only in the suboptimal temperature range and thus, in case of S. aureus 2064, the experimental data obtained at $43^{\circ} \mathrm{C}$ and $46^{\circ} \mathrm{C}$ were excluded. The RTKsub model parameters and evaluation indices are summarized in Table 1. From statistical evaluation as well from

$$
\begin{gathered}
\tau(T)=\frac{\left(T-T_{\max }\right)\left(T-T_{\min }\right)^{2}}{\left(T_{\mathrm{opt}}-T_{\min }\right)\left[\left(T_{\mathrm{opt}}-T_{\min }\right)\left(T-T_{\mathrm{opt}}\right)-\left(T_{\mathrm{opt}}-T_{\max }\right)\left(T_{\mathrm{opt}}+T_{\min }-2 T\right)\right]} \\
\gamma\left(a_{w}\right)=\frac{\left(a_{w}-a_{w \max }\right)\left(a_{w}-a_{w \min }\right)^{2}}{\left(a_{w \mathrm{opt}}-a_{w \min }\right)\left[\left(a_{w \mathrm{opt}}-a_{w \min }\right)\left(a_{w}-a_{w \mathrm{opt}}\right)-\left(a_{w \mathrm{opt}}-a_{w \max }\right)\left(a_{w \mathrm{opt}}+a_{w \min }-2 a_{w}\right)\right]}
\end{gathered}
$$




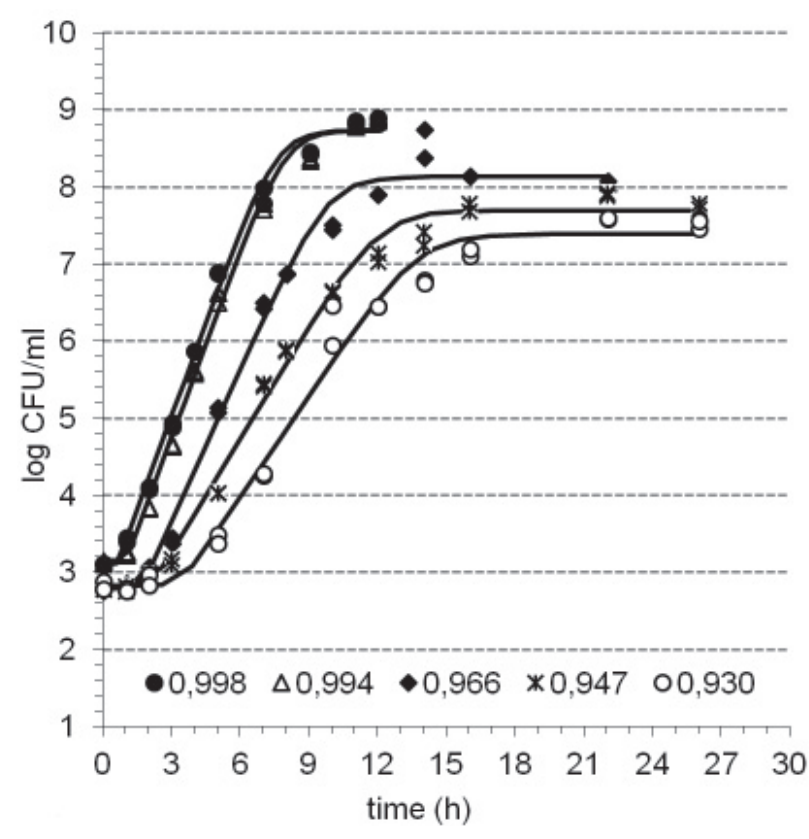

a)

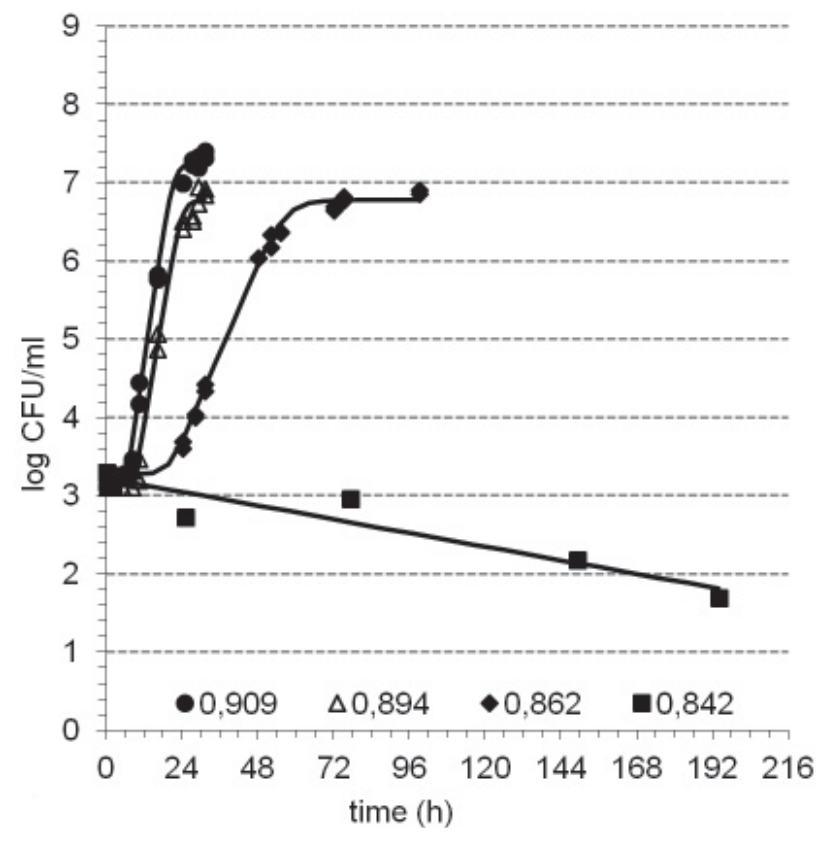

b)

Fig. 1. Growth curves of S. aureus 2064 in GTYE broth at $39^{\circ} \mathrm{C}$ in dependence on $a_{w}$ modelled by primary model of Baranyi and Roberts (1994).

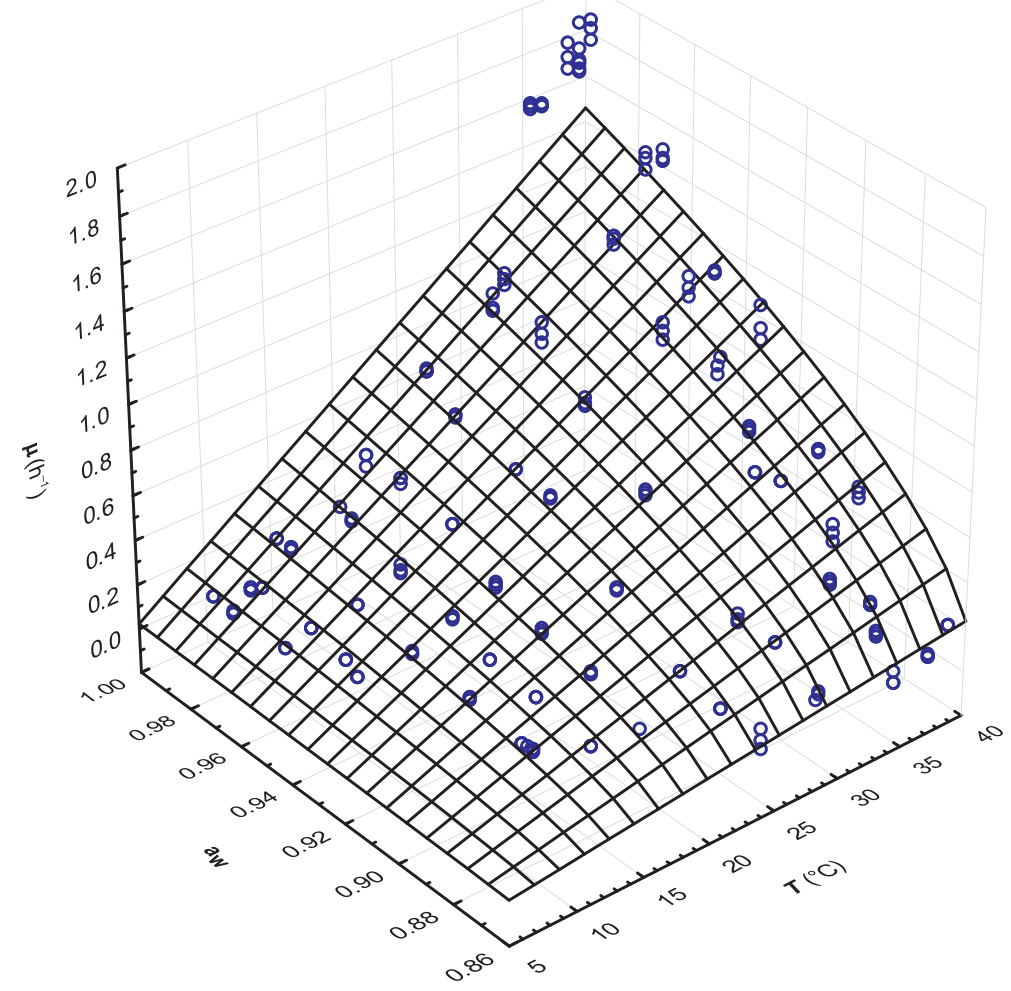

Fig. 2. Graphical presentation of RTKsub model of the effect of $a_{w}$ and $T$ in the suboptimal range $\left(10^{\circ} \mathrm{C}-39^{\circ} \mathrm{C}\right)$ on the specific growth rate of $S$. aureus $2064(n=209)$.

graphical presentation of the model (Fig. 2), the highest variance occurred and the linearity of the model was disrupted at temperatures close to the optimal one. Further increase of the incubation temperature led to slower growth rate and subse- quent change of the linear trend of the model line, as the curvature appeared at higher temperatures. So, to model the effect of temperature in the whole temperature range allowing the growth of selected microorganism, the RTKext (Eq. 2) was used. 
The whole $a_{w}$ region was included into modelling similarly as in the previous case, but also the whole $T$ region was accounted for. RTKext was an appropriate model for the $S$. aureus 2064 growth rate in dependence on these two environmental factors; their simultaneous effect on specific growth rate of S. aureus 2064 is depicted in Fig. 3. As it can be seen, the specific growth rate increased with a constant slope with the incubation temperature increase up to $40{ }^{\circ} \mathrm{C}$. At temperatures above $40{ }^{\circ} \mathrm{C}$, the growth of $S$. aureus slowed down at all $a_{w}$ values. Therefore, the curvature is observed in the optimal region, i.e. 35-40 ${ }^{\circ} \mathrm{C}$. Asperger and Zangerl (2003) or Normanno et al. (2007) also confirmed the mesophilic character of $S$. aureus with the optimum temperature in the range from $37^{\circ} \mathrm{C}$ to $40{ }^{\circ} \mathrm{C}$. Regarding the effect of $a_{w}$, the increase of specific growth rate with the increase of $a_{w}$ value also shows a constant slope and a very small curvature at the $a_{w}$ value of about 0.994 (however, not as significant as in case of temperature). A slightly lower $a_{w}$ or small amounts of $\mathrm{NaCl}(1.5 \%)$ in media are needed to reach more intensive growth as was also confirmed by Cebrián et al. (2015).

Response of S. aureus 2064 to the simultaneous influence of changing temperature and $a_{w}$ values fitted by the RTKext model is described by the following equation, with defined degree of reliability given by validation indices summarized in Table 1:

$$
\begin{gathered}
\mu_{\max }=0.0144 \times \\
\times\left[\left(T-T_{\min }\right) \times\left\{1-\exp \left[0.3345-\left(T-T_{\max }\right)\right]\right\}\right]^{2} \times \\
\times\left(a_{w}-a_{w, \min }\right) \times\left\{1-\exp \left[1241.9\left(a_{w}-a_{w, \max }\right)\right]\right\}
\end{gathered}
$$

An advantage of the RTKext model is that it is able to provide definition of cardinal values of modelled environmental factors. So, applying this model for $S$. aureus 2064 growth data set, $T_{\min }=6.06{ }^{\circ} \mathrm{C}$, $T_{\max }=47.9{ }^{\circ} \mathrm{C}$ and $a_{w \text { min }}=0.859$ were calculated. Although the RTKext model proved its appropriateness, it can provide only three cardinal values. In this context, application of the CM model is more complex. According to the CM model in combination with a global fit, seven parameters of the CM model, i.e. cardinal temperatures $\left(T_{\min }=7.72{ }^{\circ} \mathrm{C}\right.$, $T_{\text {opt }}=40.63{ }^{\circ} \mathrm{C}, T_{\max }=46.73{ }^{\circ} \mathrm{C}$ ), cardinal $a_{w}$ values $\left(a_{w \min }=0.808, a_{w \mathrm{opt}}=0.994, a_{w \max }\right.$ fixed to 1$)$ and the optimal growth rate $\left(\mu_{\mathrm{opt}}=1.97 \mathrm{~h}^{-1}\right)$ were determined.

Differences between the calculated cardinal values, i.e. about $1^{\circ} \mathrm{C}$ in the minimum and maximum temperatures and about 0.05 of $a_{w}$, may result from different approaches that both models use for fitting to experimental data set. The RTKext model offers a wider temperature range; however, applying the CM model allows the isolate to grow at higher $\mathrm{NaCl}$ addition (at about $22 \%$ ). Based on validation indices, both models proved their appropriateness, however, CM model is preferred based on higher $R^{2}$ and $\% V$ coefficients and lower RMSE and SEP indices.

Besides mathematical evaluation of the goodness of fit of the models, also graphical comparison of predicted $\left(\mu_{\text {calc }}\right)$ and experimental $\left(\mu_{\text {exp }}\right)$ values of $S$. aureus 2064 specific growth rates was performed (Fig. 4). From Fig. 4 it is obvious that RTKext and CM are more suitable for the prediction of S. aureus

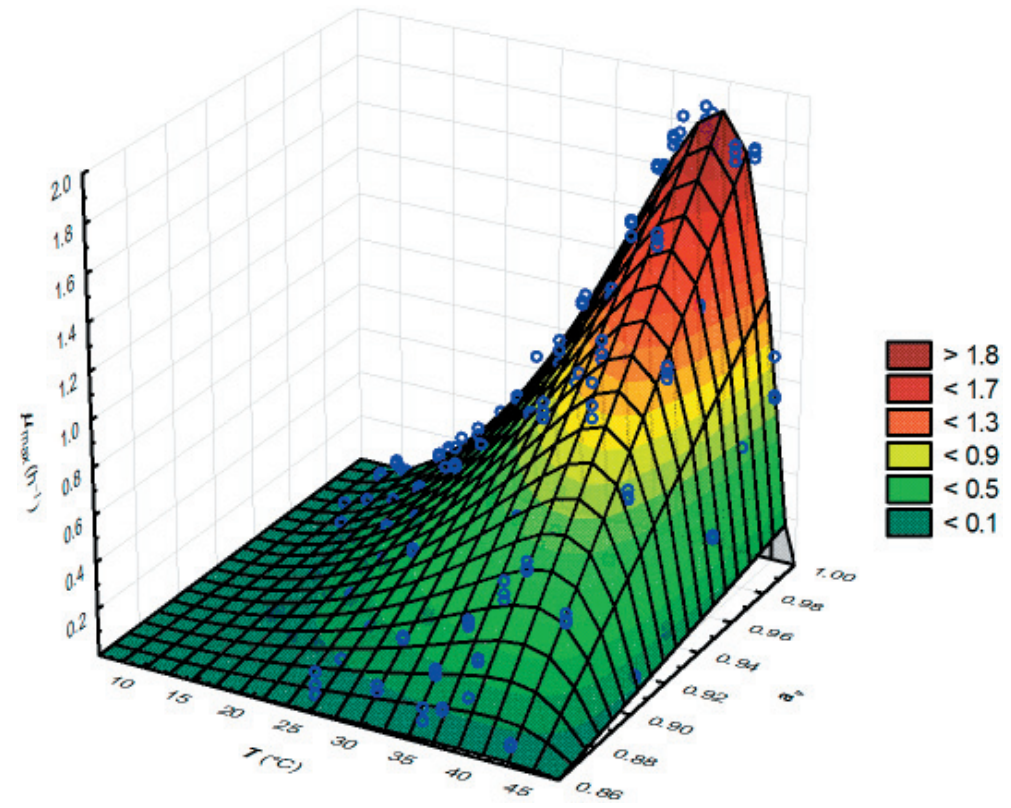

Fig. 3. Simultaneous effect of temperature and $a_{w}$ on the specific growth rate of S. aureus $2064(n=247)$ modelled by RTKext in the whole studied ranges of temperature and $a_{w}$. 


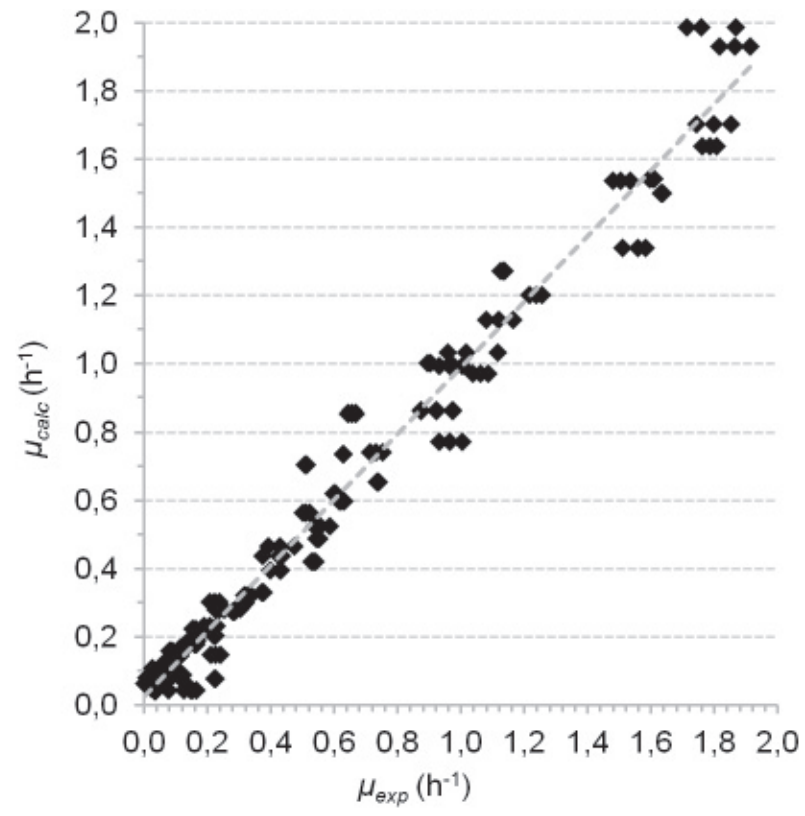

a)

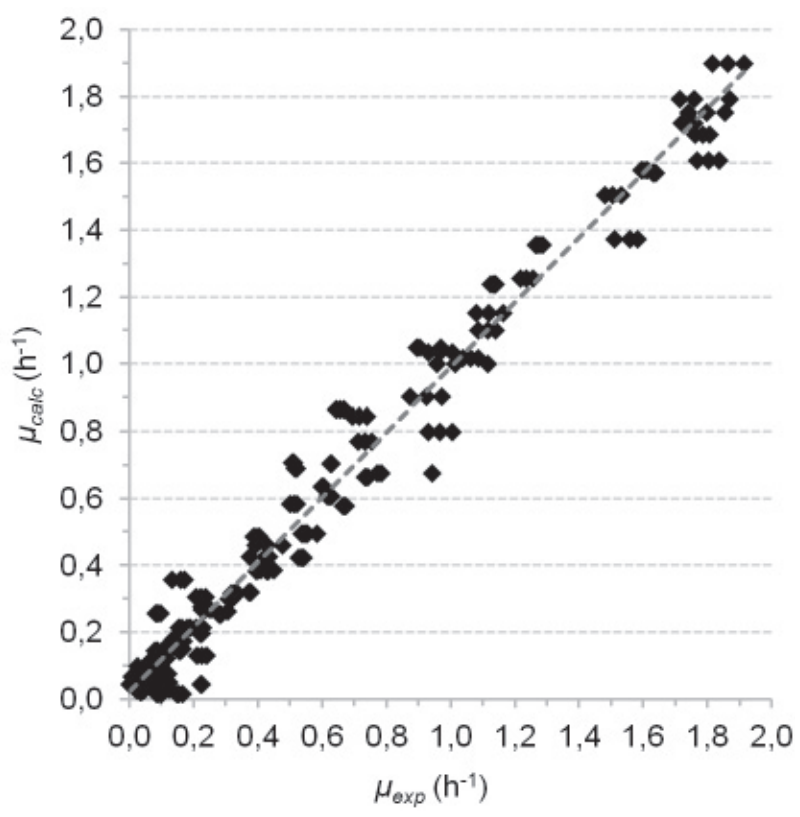

b)

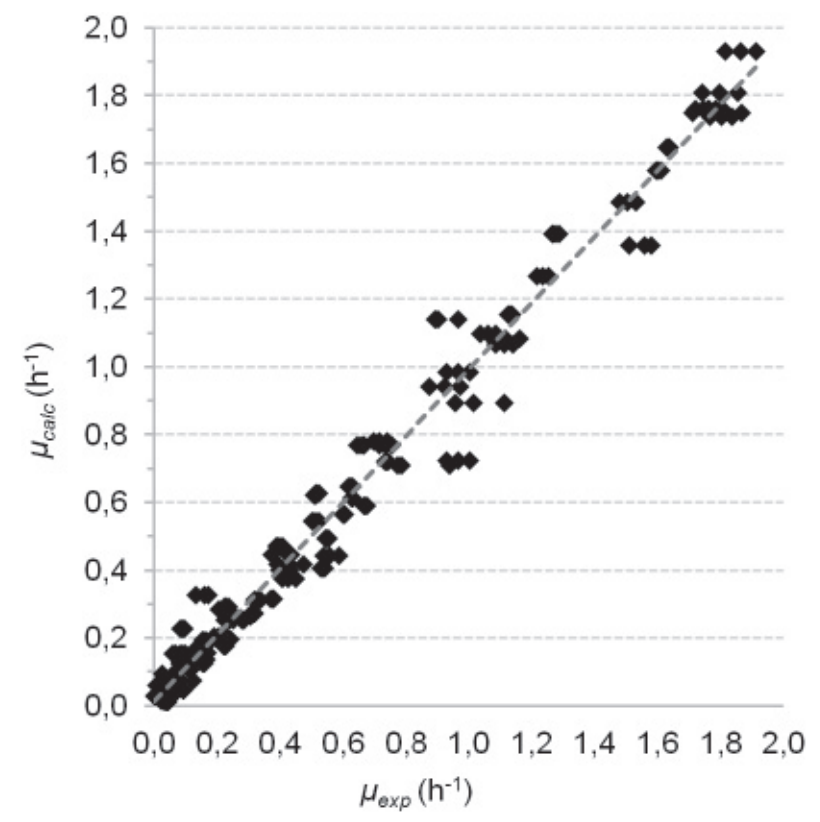

c)

Fig. 4. Comparisons of $\mu$-values of S. aureus 2064 estimated with RTKsub (4a), RTKext (4b) and CM models (4c) with experimental values.

growth in dependence on temperature and $a_{w}$ in the whole range of food environmental factors.

\section{Conclusion}

Usefulness of predictive microbiology has been pointed out for the simultaneous effect of temperature and water activity on the growth of $S$. aureus 2064. The process of predictive modelling was presented with the pros and cons of some secondary models. Moreover, cardinal temperatures $\left(T_{\min }=\right.$ $\left.=6.06-7.72^{\circ} \mathrm{C}, T_{\text {opt }}=40.63^{\circ} \mathrm{C}, T_{\max }=46.73-47.9^{\circ} \mathrm{C}\right)$ and water activity $\left(a_{w \text { min }}=0.808-0.859, a_{w \text { opt }}=0.994\right)$ of $S$. aureus 2064 and its optimal $\mu=1.97 \mathrm{~h}^{-1}$ at both optimal factors were calculated. The presented results can be applied in the control of the S. aureus growth and potential staphylococcal enterotoxins production in food practice and research.

\section{Acknowledgment}

This work was financed by the Slovak Research and Development Agency (Contract No. APVV-15-006) and the 
Tab. 1. Parameters of models and validation indices for RTKsub, RTKext and CTMI models used for the prediction of $S$. aureus 2064 growth in dependence on temperature and $a_{w}$.

\begin{tabular}{lccc}
\hline Model & RTKsub & RTKext & CTMI \\
parameters & & & \\
\hline $\mathrm{b}$ & 0.1085 & 0.0144 & - \\
$\mathrm{c}$ & - & 0.3345 & - \\
$\mathrm{d}$ & - & 1241.9 & - \\
$\mu_{\mathrm{opt}}$ & - & & 1.97 \\
$T_{\min }$ & 4.45 & 6.06 & 7.72 \\
$T_{\mathrm{opt}}$ & - & & 40.63 \\
$T_{\max }$ & - & 47.91 & 46.73 \\
$a_{w \min }$ & 0.857 & 0.859 & 0.808 \\
$a_{w \text { opt }}$ & - & & 0.994 \\
$a_{w \max }$ & - & $1(\mathrm{fixed})$ & $1(\mathrm{fixed})$ \\
\hline$n$ & 209 & 247 & 247 \\
$R^{2}$ & 0.977 & 0.977 & 0.983 \\
$R M S E$ & 0.0824 & 0.0847 & 0.0732 \\
$S E P$ & 0.158 & 0.152 & 0.073 \\
$\% V$ & 97.7 & 97.6 & 98.2 \\
\hline
\end{tabular}

Scientific Grant Agency of the Ministry of Education of the Slovak Republic and Slovak Academy of Science - VEGA 1/0532/18.

\section{References}

Arbuthnott J, Coleman D, DeAzavedo J (1990) Journal of Applied Bacteriology Symposium Supplement 69: 1S-8S.

Asperger H, Zangerl P (2003) In: Roginski H, Fuquay J, Fox P (Eds) Encyclopedia of Dairy Science (pp 2563-2569). Academic Press, San Diego.

Baranyi J, Roberts TA (1994) International Journal of Food Microbiology 26: 199-218.

Baranyi J, Roberts TA, McClure P (1993) Food Microbiology 10: 43-59.

Cebrián G, Arroyo C, Condón S, Mañas P (2015) International Journal of Food Microbiology 214: 83-90.

Daughtry BJ, Davey KR, King KD (1997) Food Microbiology 14: 21-30.

Dubois-Brissonnet F, Guillier L, Naitali M (2015) International Journal of Food Studies 4: 134-140.

ECDC (2017) Antimicrobial resistance surveillance in Europe 2015, Surveillance report, Avialable in
May 2017: http://ecdc.europa.eu/en/publications/ Publications/antimicrobial-resistance-europe-2015.

The European Union Summary Report on Trends and Sources of Zoonoses, Zoonotic Agents and Food-borne Outbreaks in 2017 (2018). EFSA Journal 16(12): 5500.

The European Union Summary Report on Trends and Sources of Zoonoses, Zoonotic Agents and Food-borne Outbreaks in 2016 (2017). EFSA Journal 15(12): 5077.

Garcia D, Ramos AJ, Sanchis V, Marín S (2011) Food Microbiology 28: 406-417.

Mariutti RB, Tartaglia NR, Seyffert N, de Paula Castro TL, Arni RK, Azevedo VA, Le Loir Y, Nishifuji K (2017) In: Enany S, Alexander LEC (Eds) The rise of virulence and antibiotic resistance in Staphylococcus aureus, (pp 127-143). InTech, Rijeka.

McMeekin T, Bowman J, McQuestin O, Mellefont L, Ross T, Tamplin M (2008) International Journal of Food Microbiology 128: 2-9.

Medved’ová A, Havlíková A, Valík L' (2017) In: Enany $\mathrm{S}$, Alexander LEC (Eds) The rise of virulence and antibiotic resistance in Staphylococcus aureus, (pp 145-167). InTech, Rijeka.

Medved’ová A, Valík L', Liptáková D (2011) Journal of Food and Nutrition Research 50: 193-198.

Normanno G, LaSalandra G, Dambrosio A, Quaglia NC, Corrente M, Parisi A, Santagada G, Firinu A, Crisetti E, Celano GV (2007) International Journal of Food Microbiology 115: 290-296.

Ote T, Taminiau B, Duprez JN, Dizier I, Mainil JG (2011) Veterinary Microbiology 153: 285-292.

Ratkowsky DA, Lowry RK, McMeekin TA, Stokes AN, Chandler RE (1983) Journal of Bacteriology 154: 1222-1226.

Reffuveille F, Josse J, Vallé Q, Mongaret C, Gangloff SC (2017) In: Enany S, Crotty Alexander LE (Eds.) The rise of virulence and antibiotic resistance in Staphylococcus aureus, (pp. 189-214). InTech, Zagreb.

Report on Zoonoses, alimentary diseases and diseases from water in Slovak Republic in 2017 (2018) 118 p.

Report on Zoonoses, alimentary diseases and diseases from water in Slovak Republic in 2016 (2017) 114 p.

Ross T, McMeekin TA (1994) International Journal of Food Microbiology 23: 241-264.

Rosso L, Lobry JR, Flanders JP (1993) Journal of Theoretical Biology 162: 447-463.

Rödel W, Krispien J, Leistner L (1979) Fleischwirtschaft 59: 849-851.

Valík L', Medved’ová A, Ačai P (2019) Journal of Food and Nutrition Research, in press.

Wood J (2016) Bioinformatics review 2: 15-17.

Zurera-Cosano G, Garciá-Gimeno RM, RodríguezPérez R, Hervás-Martínez C (2006) Food Control 17: 429-438.

Zwietering MH, De Koos JT, Hasenack BE, De Wit JC, Riet K (1991) Applied and Environmental Microbiology 57: 1094-1101. 